This is an electronic reprint of the original article. This reprint may differ from the original in pagination and typographic detail.

Author(s): Syynimaa, Nestori

Title: $\quad$ Method and Practical Guidelines for Overcoming Enterprise Architecture Adoption Challenges

Year: $\quad 2017$

Version:

Please cite the original version:

Syynimaa, N. (2017). Method and Practical Guidelines for Overcoming Enterprise Architecture Adoption Challenges. In S. Hammoudi, L. A. Maciaszek, M. M. Missikoff, O. Camp, \& J. Cordeiro (Eds.), ICEIS 2016: Enterprise Information Systems. 18th International Conference, ICEIS 2016, Rome, Italy, April 25-28, 2016, Revised Selected Papers (pp. 488-514). Springer. Lecture Notes in Business Information Processing, 291. https://doi.org/10.1007/978-3-319-62386-3_22

All material supplied via JYX is protected by copyright and other intellectual property rights, and duplication or sale of all or part of any of the repository collections is not permitted, except that material may be duplicated by you for your research use or educational purposes in electronic or print form. You must obtain permission for any other use. Electronic or print copies may not be offered, whether for sale or otherwise to anyone who is not an authorised user. 


\title{
Method and Practical Guidelines for Overcoming Enterprise Architecture Adoption Challenges
}

\author{
Nestori Syynimaa \\ Department of Computer Science and Information Systems, Faculty of Information \\ Technology, University of Jyväskylä, Finland \\ Founder and Principal Consultant, Gerenios Ltd, Tampere, Finland \\ nestori.syynimaa@gmail.com
}

\begin{abstract}
During the last few years, interest towards Enterprise Architecture (EA) has increased, not least due to anticipated benefits resulting from adopting it. For instance, EA has been argued to provide cost reduction, technology standardisation, process improvement, and strategic differentiation. Despite these benefits, the EA adoption rate and maturity are still low. Consequently, EA benefits are not realised. A major reason hindering the adoption is that EA is not understood correctly. This paper aims for minimising the effect of the lack of understanding EA to adopting EA. Based on the research conducted in Finnish public sector, we propose an improved Enterprise Architecture Adoption Method (EAAM) to overcome the EA adoption challenges. EAAM is built using Design Science approach and evaluated using Delphi method. Some practical guidelines for applying EAAM are also provided to help organisations to overcome EA adoption challenges.
\end{abstract}

Keywords: Enterprise Architecture, Adoption Method, Design Science, Delphi, Guidelines

\section{Introduction}

Enterprise Architecture (EA) has received a lot of attention during the last decades. In the last couple of years the interest has increased dramatically. Leading scientific conferences, such as ICEIS, even has a separate track dedicated to EA. One of the reasons for the increased interest is the number of anticipated benefits resulting from adopting EA. For instance, EA has been argued to provide cost reduction, technology standardisation, process improvement, and strategic differentiation [1]. Using a set of case-studies, Ross et al. [2] demonstrated how these benefits could create sustainable value to organisations. Despite these and other benefits to be gained, EA is not widely adopted in organisations [3, 4].

In this paper, we propose an improved EA adoption method and provide some practical guidelines to help organisations to adopt EA and, concequently, realise the EA benefits.

The structure of the paper is as follows. First, in this section, we introduce the key concepts of EA, the traditional EA adoption process, and some adoption challenges. Research methodology used in the paper is introduced in section 2. Our proposal of 
improved Enterprise Architecture Adoption Method (EAAM) is introduced in section 3 , followed by some practical guidelines in section 4 . Section 5 concludes the paper, including some directions for the future research.

\subsection{Enterprise Architecture}

Enterprise Architecture has many definitions in the current literature. Vague definitions are confusing both practitioners and scholars [5-9]. EA is seen as a verb, something we do, and as a noun, something we produce [10]. From the various definitions in the literature [11-16] we adopt the following synthesis: "Enterprise Architecture can be defined as; (i) a formal description of the current and future state(s) of an organisation, and (ii) a managed change between these states to meet organisation's stakeholders' goals and to create value to the organisation" [17]. As such, we accept the double meaning of EA as a noun and a verb.

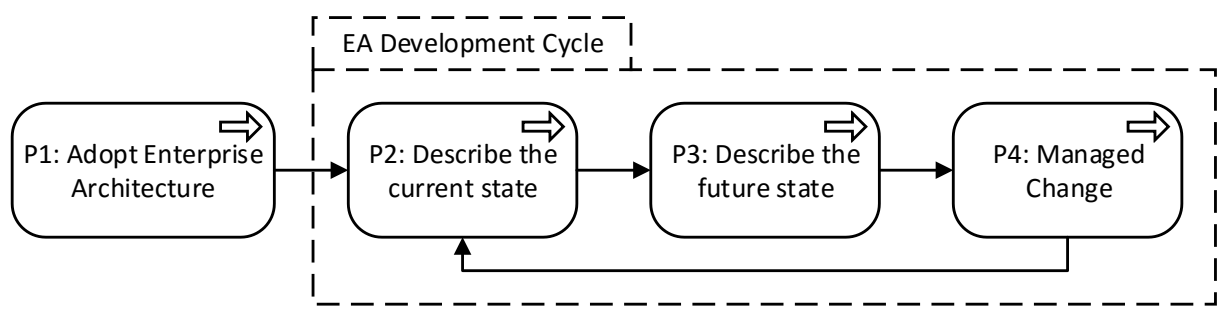

Fig. 1. Enterprise Architecture Processes

With this definition in mind, we can identify three processes related to $E A$ development cycle as illustrated in Fig. 1 using ArchiMate notation. The first process (P2) is describing the current state of the organisation. The second process (P3) is describing the future state of the organisation. Difference between these two is that P2 is merely a description of the current state of the organisation, whereas $\mathrm{P} 3$ includes also elements of planning. The third process ( $\mathrm{P} 4)$ is the managed change where the (planned) future state of the organisation is implemented. There is also a fourth process related to $\mathrm{EA}$, the adoption ( $\mathrm{P} 1)$, which precedes the other three processes. During the adoption the state of the organisation is changes from the state where EA is not adopted to the state where it is adopted.

\subsection{Enterprise Architecture Adoption}

We define Enterprise Architecture adoption as a process, where an organisation starts using EA methods and tools for the very first time. It is an instance of teleological organisational change aiming for the realisation of EA benefits, e.g., change for a purpose [18]. 


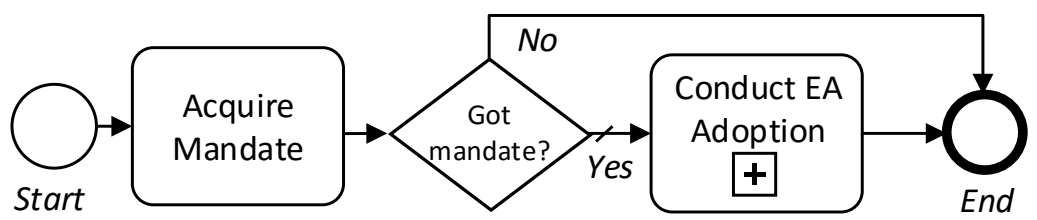

Fig. 2. Traditional EA Adoption Process

The traditional EA adoption process is illustrated in Fig. 2 using BPMN 2.0 notation. It is a high level process consisting of two activities. The mandate for the EA adoption is seen crucial by both scholars and practitioners [19-29]. Therefore the first activity is to acquire a mandate for EA adoption. If the mandate is not given the adoption process terminates. If the mandate is given the process continues to the another activity called Conduct EA adoption. This collapsed sub-process is expanded in Fig. 3.

The first task in the Conduct EA Adoption process is to select EA framework. EA frameworks, such as TOGAF, usually consists of a development method and a governance model which are distinctive to the framework. Therefore the remaining tasks of the process depends on the selected framework. As it can be noted, the remaining tasks are same than the processes $\mathrm{P} 2, \mathrm{P} 3$, and $\mathrm{P} 4$. This is because during the adoption these steps are executed once before entering the normal EA development cycle.

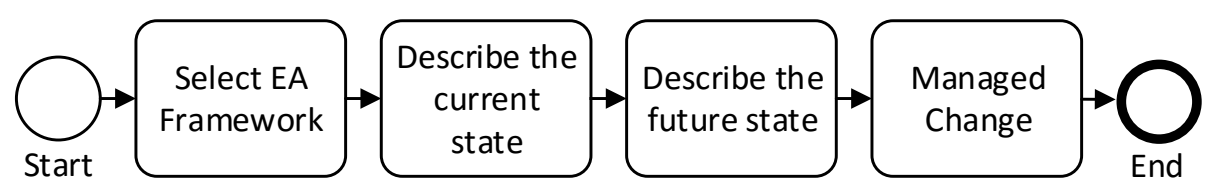

Fig. 3. Conduct EA Adoption Process

\subsection{EA Adoption Challenges}

As stated, EA adoption is an organisational change aiming for the realisation of EA benefits. About 70 per cent of organisational change initiatives fail [30-32]. This is also the case with EA adoption. Consequently, the anticipated benefits of the adoption are not realised.

For instance, in Finland, EA is made mandatory in public sector by legistlation [33]. The Act of Information Management Governance in Public Administration requires public sector organisations to adopt EA by 2014. In 2014 the EA maturity in state administration was 2.6 or below in the 5 level TOGAF maturity-model [34]. Several studies has found that EA is not well understood in Finnish public sector [8, 35-37]. According to recent PhD studies $[36,37]$ the lack of EA knowledge is one of the main reasons hindering EA adoption 


\section{$2 \quad$ Research Methodology}

In this paper we have adopted Design Science (DS) approach [38] to improve the traditional EA adoption method. DS is a research approach aiming to develop scientific knowledge by designing and building artefacts [39]. As such, DS is concerned about the utility value of the resulting artefacts [40]. There are three types of artefacts to research: (i) a technology artefact, (ii) an information artefact, and (iii) a social artefact [41]. In this paper we are building a method, which according can be categorised as a technology artefact [41].

This paper follows Design Science Research Model (DSRM) by Peffers et al. [42]. DSRM process consists of six phases: (i) problem identification and motivation, (ii) defining objectives for a solution, (iii) designing and developing an artefact, (iv) demonstration of the usage of the artefact, (v) evaluation of artefact's utility, and (vi) communication.

Typical outcome of DS is a tested and grounded Technological Rule (TR), which can be defined as "a chunk of general knowledge, linking an intervention or artefact with a desired outcome or performance in a certain field of application" [39, p. 228]. The form of a TR is "if you want to achieve $\mathrm{Y}$ in situation $\mathrm{Z}$, then perform action $\mathrm{X}$ " $[39$, p. 227]. Tested TR means a rule which has been tested in the context it is intented to be used [43]. Grounded TR (GTR) is a rule which reasons for its effectivness are known [43, 44]. In this paper, we will seek for GTRs which would improve the traditional EA adoption method.

EA adoption is a process where the current state of the organisation is changed. This is comparable to the DS problem-solving situation illustrated in Fig. 4. The desired state of EA adoption is the organisation where EA is adopted and embedded to organisation's processes. However, it is possible to end up with a final state where the desired state is not achieved or it is achieved only partially.

In order to evaluate whether the improved EA adoption method works as intented, we should perform the adoption using the method in a real-life setting. Given the time and resources required by EA adoption, real-life evaluation is practically not possible. Therefore, we will adopt a Delphi method to evaluate the utility of the method.

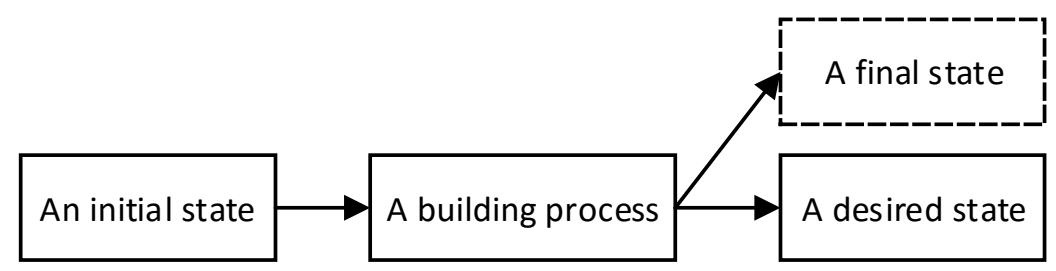

Fig. 4. DS problem-solving situation [45]

Delphi method is a research process where experts' judgements about the subject are iteratively and anomynously collected and refined by feedback [46]. It is typically used in forecasting but can be used also when developing and evaluating methods [47]. 


\section{Enterprise Architecture Adoption Method}

In this section we will introduce the Enterprise Architecture Adoption Method (EAAM) and describe its building process and evaluation. The section is organised following the phases of DSRM process.

\subsection{Problem Definition and Objectives}

As stated earlier, various studies have noticed the lack of EA knowledge in the Finnish public sector. For instance, it has been argued that current definitions of EA are inconsistent and thus confusing both researchers and practitioners [8]. This is a problem especially among practitioners; "EA was not thoroughly understood by the public sector authorities." [8, p. 170]. This is supported by other study [35]; EA is underutilised due to lack of understanding it properly. In general, poor communication have been found to be one of the factors contributing to EA adoption failures [27]. This problematic also because the perceived value of EA is directly influenced by how EA is understood [48]. Thus it can be argued that the lack of understanding of EA concepts is a major cause hindering EA adoption. As such, it is important to minimise or remove this cause. Therefore, our problem definition for EAAM is as follows: How to minimise the effects of the lack of understanding EA concepts to EA adoption process? This leads us to the objective of the EAAM, which is to improve the traditional EA adoption method to minimise the effect of lack of understanding of EA concepts.

\subsection{Design and Development}

In this sub-section the concepts and theories related to organisational change are introduced and discussed.

\subsubsection{Readiness for Change}

Besides organisation culture [49], also readiness for change has an impact on successful change [50].

According to Holt et al. [51] the most influential factors of change readiness are (i) discrepancy (the belief that a change was necessary), (ii) efficacy (the belief that the change could be implemented), (iii) organisational valence (the belief that the change would be organizationally beneficial), (iv) management support (the belief that the organizational leaders were committed to the change), and (v) personal valence (the belief that the change would be personally beneficial). [51]. This implies that the content, context, and process of EA adoption together with individual attributes affects the readiness for EA adoption. More specifically, individuals should believe that EA adoption is necessary, possible, beneficial to organisation, and supported by topmanagement. They should also feel that EA adoption would be beneficial to themselves. Similarly, managers who understand the change efforts are more less resistant to change [52].

Communication has an important role in organisational change. It has a positive effect to the readiness for change [53]. On the other hand, uncertainty has a negative 
effect to readiness for change, which can be influenced by communication. This implies that readiness for EA adoption can be increased by communication, either directly or by decreasing uncertainty.

General acceptance models [see for example 54] suggests that individual acceptance of information technology (IT) is influenced by beliefs and attitudes, which in turn is influenced by Managerial interventions and Individual differences Individual acceptance is concpetually similar to the readiness for change. Both are influenced by beliefs and attitudes. These beliefs can be influenced by managerial intervention, e.g., communication. Therefore, in order to increase the likelihood of EA adoption success, the readiness for change needs to be increased by a proper communication by managers.

\subsubsection{Individual and Organisational Learning}

Learning can be defined as a transformation where "the initial state in the learner's mind is transformed to the new state which is different from the initial state if learning has occurred." [55, p. 14, italics removed]. State of mind consists of following cognitive beliefs; beliefs (knowledge), values, and know-how. Skills are included in know-how. If learning occurs, the state of mind is transferred to a new state of mind with different cognitive beliefs. Learning can occur through acts in reality or by learner's own thinking. The former learning mode means learning by perceptions, by having new experiences, or by acquiring information. [55].

The current position of IS research is rooted in methodological individualism, which sees organisations as collection of individuals [56]. This theoretical point of view is problematic, as it suggests that if the new people are coming in to the organisation, a new organisation would emerge [57]. Therefore, according to Lee [57], the better conceptualisation would be that the organisation stays (somewhat) the same, and the people moving in would change towards the organisation's culture.

Organisational learning can be explained using 4I framework, where learning occurs on individual, group, and organisational levels. These levels are linked by four processes; intuiting, interpreting, integrating, and institutionalising. "Intuiting is a subconscious process that occurs at the level of the individual. It is the start of learning and must happen in a single mind. Interpreting then picks up on the conscious elements of this individual learning and shares it at the group level. Integrating follows to change collective understanding at the group level and bridges to the level of the whole organization. Finally, institutionalising incorporates that learning across the organization by imbedding it in its systems, structures, routines, and practices" [58, p. 212].

Individual learning is in a crucial part on the organisational learning, as organisations are "after all, a collection of people and what the organisation does is done by people" [59]. Also, "change is not just about how people act, but it is also about how they think as well." [60, p. 49]. It can said that organisational learning has occurred, when EA concepts are understood on individual level, and EA processes and methods adopted and embedded to organisation's routines.

Individual and organisational learning has direct implications to EA adoption. Organisational level learning occurs only through individuals. Similarly, individuals learn from the organisation. However, organisation is not the only source of learning for individuals. Learning may occur whenever the individual is interacting with the 
reality (i.e., communicating, perceiving, observing) but also by barely thinking [55]. Therefore, in order to adopt EA in an organisation, individuals of the organisation needs to learn EA.

\subsubsection{Effects of EA Training and Understanding EA Benefits}

Hazen et al. [61] studied why EA is not used to a degree which realises its benefits. The study is based on the UTAUT by Venkatesh et al. [54]. The study is especially interested in which performance expectancy drives organisational acceptance of EA. Performance expectancy is defined as "the degree to which an individual believes that using the system will help him or her to attain gains in job performance" [54, p. 447]. According to findings, partial mediation model explains the EA use significantly more than full or no mediation models. The partial mediation model implies that in order to increase EA knowledge, individuals' performance expectancy of EA needs to be increased along with proper EA training.

Nassiff [48] studied why EA is not more widely adopted, by analysing how organisation's executives value EA. According to his findings, EA has four meanings among executives; Business and IT alignment, a holistic representation of the enterprise, a planned vision of the enterprise, and a process, methodology, or framework enhancing enterprise decision making. Also 16 unique benefits of EA were identified. Value of EA is directly influenced by how the EA is understood in the organisation. Regardless of the meaning of EA, three common benefits were expected; alignment between business and IT, better decisions making, and the simplification of system or architecture management. Findings implies that in order to increase the individual's performance expectancy of EA adoption, EA benefits needs to be communicated according to what EA means to the individual. This implication actually means also adopting andragogy instead of pedagogy as an assumption of learning; individual learning is depending on and occurring on top of the past experiences of the individual [62]. These past experiences and existing "knowledge" can have a negative effect to learning EA adoption, as individuals "have a strong tendency to reject ideas that fail to fit our preconceptions" [63, p. 5].

\subsubsection{Role of Managerial Intervention and Leadership Style}

Makiya [64] has studied factors influencing EA assimilation within the U.S. federal government. EA was adopted gradually, starting from adoption (as defined in this paper) ending to assimilating EA as an integral part of organisation. The research was divided in to three three-year phases. During the first phase (e.g., adoption) factors like parochialisms and cultural resistance, organisation complexity, and organisation scope had a significant influence. According to the findings, parochialisms and cultural resistance did not exist in phase two, likely due to coercive pressure by organisation. This can be interpreted so that by using a force mandated by organisational position, one can greatly influence EA adoption. This is conceptually similar to managerial intervention, but also to situational and social influence. It should be noted that this approach had no effect in the phase three, so it should be utilised only during the adoption phase. According to study, labelling EA as an administrative innovation instead of a strategic tool could help in value perception and adoption of EA. 
Vera and Crossan [65] has expanded the model of organisational learning by Crossan et al. [66]. They added the concept of learning stocks. Learning stocks exists in each level of organisational learning, namely individual, group, and organisation levels. These learning stocks contains the inputs and outputs of learning processes, taking place between layers. They argue that different leadership styles (transactional or transformational) needs to be used based on which type of organisational learning (feed-forward of feedback) needs to be promoted.

There are some behavioural differences between transactional and transformational leadership styles. These styles are not exclusive but should be used accordingly based on the situation [65]. Transactional leadership is based on "transactions" between the manager and employees [67]. They are performing their managerial tasks by rewards and by either actively or passively handling any exceptions to agreed employee actions. Transformational leadership style aims to elevating the interests of employees by generating awareness and acceptance of the purpose of the group or initiative [67]. This is achieved by utilising charisma, through inspiring, intellectual stimulation, and by giving personal attention to employees. Thus it can be argued that transactional leadership style suits better in a situation where status quo should be maintained. Similarly, transformational leadership style works better in a situation where organisation faces changes.

The feed-forward learning allows organisation to innovate and renew, whereas the feedback process reinforces what has already learned. There can be two types learning; learning that reinforces institutionalised learning and learning that challenges institutionalised learning. Transformational leadership have a positive impact to learning when current institutionalised learning is challenged, and when organisation is in a turbulent situation. In turn, transactional leadership have positive impact to learning when the institutionalised learning is reinforced, and when organisation is in a steady phase. [65].

The role of managerial or leadership style to organisational and individual learning is significant. The key is the current organisational learning stock or institutionalised learning regarding to EA adoption. If EA adoption conflicts with the current institutionalised learning, the transformational leadership should be used in order increase the feed-forward learning. Vice versa, if EA adoption does not conflict with the current institutionalised learning, the transactional leadership should be used to increase feedback learning.

Espinosa et al. [68] have studied the coordination of EA, focusing on increasing understanding how coordination and best practices lead to EA success. According to study, cognitive coordination plays a critical role in effectiveness of architecting. Their model consists of two models, static and dynamic models. Whereas the static model affects the effectiveness on "daily basis", a dynamic model strengthens group cognition over the time. There are three coordination processes in the model: organic, mechanistic, and cognitive. Mechanistic coordination refers to coordination of the routine aspects with minimal communication by using processes, routines, specification, etc. Organic coordination refers to communication processes used in more uncertain and less routine tasks. Cognitive coordination is achieved implicitly when each collaborator have knowledge about each other's tasks, helping them to anticipate and thus coordinate with a reduced but more effective communication. As it can be noted, the term "cognitive" is not referring to term cognition, which is usually 
defined as a "mental action or process of acquiring knowledge and understanding through thought, experience, and the senses" [69]. Instead, they are referring to the shared cognition of a high performance group of individuals having similar or compatible knowledge, which can coordinate its actions without the need for communication [70].

According to the findings by Espinosa et al. [68], cognitive coordination plays a central role in strengthening the other two coordination mechanisms. Therefore, in order increase the effectiveness of EA adoption, the shared cognition of individuals within the organisation needs to be strengthened. This can be achieved by providing similar level of EA knowledge to all individuals

\subsubsection{Emerging EA Adoption Method}

In this sub-section, we first sum up the concepts presented in previous sub-sections and form a list of propositions based on these concepts and their interrelations (Table 1). Based on these proposition, six Ground Technological Rules (GTRs) are presented (Table 2), and finally EAAM process descriptions are introduced.

Table 1. Propositions of EA Adoption Method

\begin{tabular}{|c|c|c|}
\hline ID & Explanation & Source \\
\hline $\mathrm{P} 1$ & $\begin{array}{lllll}\text { Understanding } & \text { EA } & \text { Benefits } & \text { influences } & \text { Performance } \\
\text { Expectancy } & & & & \\
\end{array}$ & Nassiff [48] \\
\hline $\mathrm{P} 2$ & $\begin{array}{l}\text { Executive's understanding of EA meaning influences } \\
\text { benefits }\end{array}$ & Nassiff [48] \\
\hline $\mathrm{P} 3$ & Performance Expectancy influences EA training & Hazen et al. [61] \\
\hline $\mathrm{P} 4$ & $\begin{array}{l}\text { Individual's and organisation's learning stocks influences } \\
\text { each other }\end{array}$ & Crossan et al. [66] \\
\hline P5 & Performance Expectancy influences EA adoption & Hazen et al. [61] \\
\hline P6 & $\begin{array}{l}\text { Managerial Intervention influences feed-forward and } \\
\text { feedback learning }\end{array}$ & Crossan et al. [66] \\
\hline P7 & Individual's learning stock influences EA Adoption & $\begin{array}{l}\text { Agarwal [71] } \\
\text { Elving [53] } \\
\text { Espinosa } \text { et al. }[68] \\
\text { Hazen } \text { et al. } \text { [61] } \\
\text { Holt } \text { et al. }[51]\end{array}$ \\
\hline P8 & Executives Individual Attributes influences leadership style & $\begin{array}{l}\text { Bass [67] } \\
\text { Crossan et al. [66] }\end{array}$ \\
\hline P9 & Managerial Invention influences EA Adoption & $\begin{array}{l}\text { Agarwal [71] } \\
\text { Makiya [64] }\end{array}$ \\
\hline
\end{tabular}

By EA Benefits we refer to all those benefits that may result of adopting Enterprise Architecture. These benefits influences Performance Expectancy $(P E)$, which refers to individual's expectations towards EA adoption (P1). Individual's Learning Stock refers to all individual's current knowledge, know-how, values, and processes related on changing these (i.e. learning). Performance Expectancy influences Individual's Learning Stock (P3) by giving some meaning to EA's performance properties. 
Performance Expectancy also has a direct influence to EA Adoption (P5). Individual's Learning Stock influences EA Adoption (P7), as it contains all individual's knowledge, know-how, and values related to Enterprise Architecture. Managers' and executives' Individual Learning Stock influences EA Benefits (P2) in terms of his or hers capability to comprehend possible benefits related to EA adoption. Similarly, managers' and executives' Individual Learning Stock influences how they are capable in using Managerial Intervention to increase EA adoption success (P8). Organisation's Learning Stock refers to the current organisation's institutionalised knowledge (i.e., patents), know-how (i.e., processes, instructions, rules), and values (i.e., culture). Feedforward and feedback learning occurs between Organisation's Learning Stock and Individual's Learning Stock (P4). As organisations are composed of its members, changes in Organisation's Learning Stock (i.e., organisational learning) may only occur through Individual's Learning Stock. Organisation's Learning Stock however is only one of many sources that influences Individual's Learning Stock. Managerial Intervention refers to those actions which organisation's managers and executives may use to increase the success of EA adoption. Managerial Intervention has a direct influence on EA Adoption (P9), as managers and executives may provide coercive pressure to "force" EA adoption. Managerial Intervention influences also organisational learning (P6) taking place between Individual's and Organisation's Learning Stocks where managers and executives may promote learning by choosing their leadership style accordingly.

Based on the propositions, six GTRs are provided in Table 2. As suggested by propositions P1, P2, P3, P4, P5, and P7, understanding EA benefits influences the EA adoption indirectly through performance expectancy and individual's learning stock. In order to acquire the mandate for EA adoption from the top-management, GTRs R1 to $\mathrm{R} 4$ are provided. As suggested by propositions P6 and P9, managerial intervention influences EA adoption indirectly by influencing organisational learning, and directly. Use GTRs R5 and R6 to influence indirect and direct learning, respectively.

Table 2. Grounded Technological Rules

\begin{tabular}{ll}
\hline ID & \multicolumn{1}{c}{ Explanation } \\
\hline R1 & $\begin{array}{l}\text { If you want to acquire a mandate for Enterprise Architecture adoption from top- } \\
\text { management, explain Common EA Benefits. }\end{array}$ \\
\hline R2 & $\begin{array}{l}\text { If you want to acquire a mandate for Enterprise Architecture adoption from top- } \\
\text { management in a situation where manager's } \\
\text { view to EA is more business oriented, } \\
\text { rating of the organisation's EA maturity is low, or EA experience is low, explain } \\
\text { Alignment Specific Benefits. }\end{array}$ \\
\hline R3 & $\begin{array}{l}\text { If you want to acquire a mandate for Enterprise Architecture adoption from top- } \\
\text { management in a situation where manager's }\end{array}$ \\
& $\begin{array}{l}\text { EA experience is high, } \\
\text { perception of EA complexity is low, or current EA authority is low, explain Planned } \\
\text { Vision Specific Benefits. }\end{array}$ \\
\hline R4 & $\begin{array}{l}\text { If you want to acquire a mandate for Enterprise Architecture adoption from top- } \\
\text { management in a situation where manager's } \\
\text { current EA authority is high, explain Decision Making Specific Benefits. }\end{array}$ \\
&
\end{tabular}




\begin{tabular}{ll}
\hline ID & \multicolumn{1}{c}{ Explanation } \\
\hline R5 & $\begin{array}{l}\text { If you want to improve organisational learning during EA adoption in a situation where } \\
\text { EA challenges the current organisational learning, use Transformational Leadership } \\
\\
\text { Style. Otherwise use Transactional Leadership Style. }\end{array}$ \\
\hline R6 & If you want to improve EA adoption, use Coercive Organisational Pressure. \\
\hline
\end{tabular}

Based on the propositions and the GTRs provided above, three process descriptions are formed using BPMN 2.0 notation. First description, EA adoption process, can be seen in Fig. 5. The process consists of four tasks; Explain EA benefits, Acquire Mandate, Organise EA learning, and Conduct EA adoption. When compared to the traditional EA adoption process seen in Fig. 2. two tasks are added. The first new task, a collapsed sub-process of Explaing EA Benefits is expanded in Fig. 6. The second new task, a collapset sub-process of Organising EA Training is explanded in Fig. 7. The logic of the process is as follows. A mandate from top management of the organisation is a requirement for EA adoption. In order to increase the likelihood of getting the mandate, one needs to explain the benefits of EA to management. If mandate is given, the next task is to organise EA training to increase the understanding of EA concepts. After these tasks are completed, the actual EA adoption can be started.

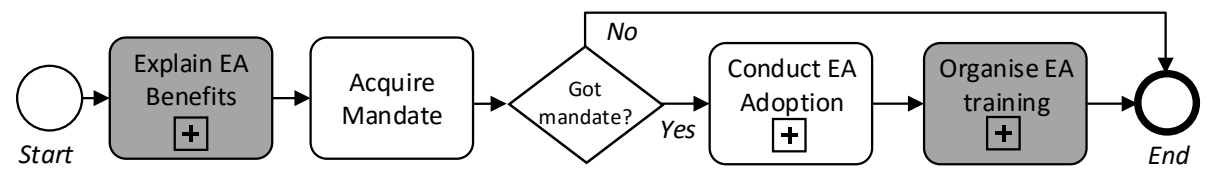

Fig. 5. Improved EA Adoption Process

The process of explaining EA benefits can be seen in Fig. 6. This process has two actors, the EA responsible and Manager. The manager refers to the manager or executive whose support to EA adoption is seen as important.

The first task of the process is to explain common EA benefits, such as alignment of business and IT. Next task is to assess manager's views to EA in terms of EA business orientation, organisation's EA maturity, EA experience, perception of EA's complexity, and current EA authority. Based on the assessments, one should explain the more specific EA benefits accordingly. For example if the manager's EA experience is low, one should explain the benefits specific to alignment, such as increased operational effectiveness and process improvements. 

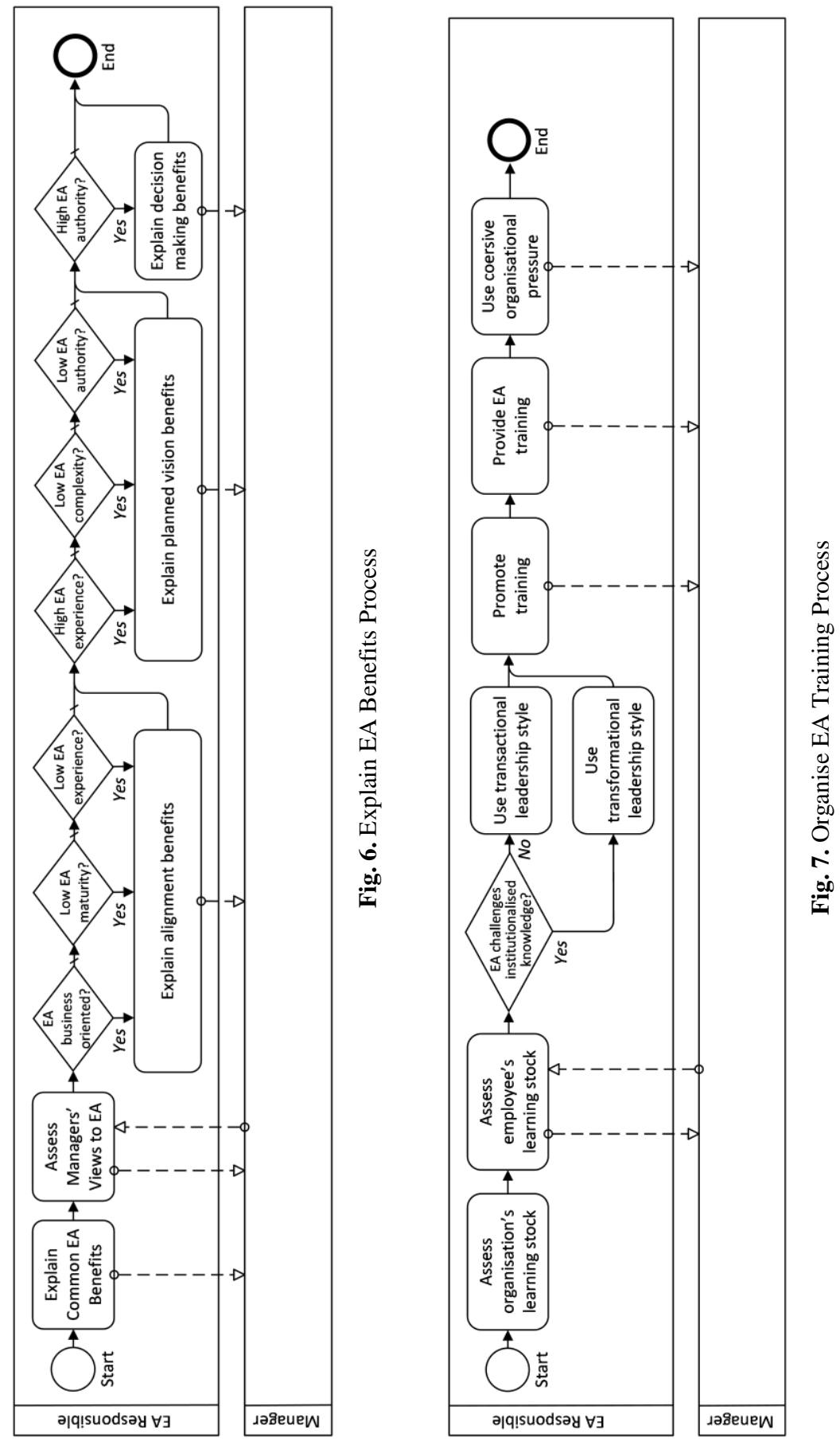
The process of providing EA training can be seen Fig. 7. This process has also two actors, EA responsible and Employees, which represents organisation's personnel. First task is to assess organisation's current learning stock, i.e. what is organisation's current knowledge, know-how, and values related to Enterprise Architecture. As we are in the adoption phase, the level of EA specific knowledge is ought to be low, but one should assess capabilities and practices such as project management, change management, and internal communication. Second task is to assess employee's learning stock. Based on these two learning stock assessments, one should choose a proper leadership style. If EA adoption challenges institutionalised learning, i.e. it is different than status quo, one should choose to use transformational leadership style. If the learning does not challenge institutionalised learning, one should choose to use transactional leadership style. By using the chosen leadership style, next task is to promote learning accordingly. Next task is to provide EA learning based on assessments of current learning stocks. The last task is to use coercive organisational pressure.

\subsection{Evaluation}

Purpose of the evaluation of our Enterprise Architecture Adoption Method (EAAM) is to assess whether it has the intended affect. The evaluation design follows the guidelines by Venable et al. [72]. Target of the evaluation is the product, EAAM, and evaluation takes place ex-post. The audience of EAAM is mainly EA responsible, i.e., EA champions, project managers, EA architects, etc.

Delphi method was selected as an evaluation method. For the evalution, a panel of top Finnish EA expert was carefully selected from both industry and academia. Panel consisted of 11 members of different roles; professors (2), CIOs (3), consultants (2), EA architects (2), and development managers/directors (2). Evaluation consists of three rounds.

For the first round, using open-ended questions, experts were asked to read the EAAM method description and compare it to the traditional adoption method. For the second round, first round answers were transformed to claims $(n=31)$ and were sent back to experts for rating (disagree-neutral-agree). The scale $(-3,-2,-1,0,1,2,3)$ was formed so that it could be treated as an interval scale as defined by Stevens [73] which allowed us to calculate mean and standard deviations. For the third round, claims were sent to experts for rating including the average opinion of the panel. This allowed experts to re-assess their opinions to each claim.

The purpose of the evaluation is to have an unanimous opinion of the experts about EAAM. Thus the interest lies in the claims having a high mean and low standard deviation. Claims were ordered by their $\mathrm{z}$-scores calculated with the formula $z=(x-\mu) / \sigma$ where $x$ is the mean value of the particular claim, $\mu$ is 0 (the centre of the scale), and $\sigma$ is the standard deviation of the particular claim. The higher the z-score is, the more unanimous are the experts. To include only the most unanimous claims, a critical zvalue for 0.95 significance was used as a threshold. The critical value for 0.95 is 1.65 as calculated by Excel 2007 NORMSINV function. Claims with the z-score less than 1.65 are thus rejected, which leaves us 16 statements of EAAM seen in Table 3. 
Table 3. Evaluation Statements

$\mathrm{z} \quad$ Statement

5.33 Considered and appropriate leadership style helps in adoption because it is all about changing the way to perform development.

4.64 Benefits of the adoption and the temporal nature of the resulting extra work is understood better, because the benefits are communicated using the target group's comprehension and point of view.

3.77 The meaning of the top-management's own example for the organisation is becoming more aware, because by the commitment of the top-management also the rest of the organisation is obligated to the EA adoption.

3.33 IM department's estimates of change targets are improved, because the anticipation of changes are improved and visualised.

2.83 The average of organisation's individuals' willingness to change will change to more positive, because the communication of benefits increases the formation of positive image and the acquirement the mandate from top-management.

2.67 The reasons for actions will be communicated.

2.67 Top-managements support to EA as a continuous part of organisation's normal management and operational development increases, because the recognition of the purpose and justification of EA-work, and communication of benefits, builds the foundation to acquire the mandate of top-management.

2.36 The total development of organisational knowledge would be improved in general, because also other actors beside the top-management are taken into account.

2.36 The leadership point of view is correct because the communication of EA is shaped according to the target group.

2.13 Setting the target and objectives of the adoption can be performed faster and in managed manner because the participants has a common picture of concepts, objectives, and methods before the actual execution phase.

2.04 The commitment and motivation to the adoption increases, because the understanding of reasons and objectives of EA increases.

1.85 Effects to the quality of results and to communicating them are positive, because the meaning of broad-enough knowledge is emphasised.

1.76 Documentation of QA system is improved, because method has a positive effect in the creation of basic documentation

1.76 Improves commitments and possibilities to acquire the mandate, because the person responsible for adoption is helped to improve targeting and content of the communication, and to considering the appropriate influencing methods and approaches.

1.76 Definitions of the roles and tasks are naturally forming according to the target, because the communication using the language of the target group affects the understanding of the benefits of each group.

1.67 Securing of top-management's commitment to adoption of EA and similar concepts increases, because the adoption is strongly based on top-management's commitment and communication of the adoption. 


\section{Some Practical Guidelines}

In this section, some practical guidelines for applying Enterprise Architecture Adoption Method are provided. The section consists of four sub-sections following the EAAM process steps, i.e., Explain Enterprise Architecture Benefits, Acquire Mandate, Organise Enterprise Architecture Training, and Conduct Enterprise Architecture Adoption.

\subsection{Explain Enterprise Architecture Benefits}

The first phase of EAAM is to explain EA benefits to the organisation's management in order to "sell" the EA adoption. In this sub-section the steps of Explain EA Benefits Process (see Fig. 6) are explained. Purpose of this step is to increase the likelihood of securing the mandate for EA adoption from the top-management.

\subsubsection{Explain common Enterprise Architecture benefits}

The first task of the Explain EA Benefits Process is to explain the common EA benefits to organisation's management. Common EA benefits are those anticipated benefits that interests and can be understood by everyone regardless of their role.

The first common benefit is the Alignment of business and IT. This refers to "applying Information Technology (IT) in an appropriate and timely way, in harmony with business strategies, goals and needs." [74, p. 3]. Alignment allows organisations to generate business value from IT. For instance, organisation can achieve strategic goals and realise business benefits [75].

The second common benefit is Make better decisions. This benefit is premised on high-quality information which supports decision making.

Third common benefit is Simplification of system or architecture management. Reduced complexity of management reduces also risks associated to managing systems of architectures.

\subsubsection{Assess managers' views to EA}

The second phase of the Explain EA Benefits Process is to assess the managers' views to EA. There are five qualities or characteristics to be assessed.

The first quality to assess is whether managers see EA as a business or technology oriented. For instance, EA can be seen as the glue between business and IT, as the link between strategy and execution, or as the means for organisational innovation and sustainability [76]. The first view to EA refers to technical orientation and the two latter ones to business orientation.

The second quality to assess is how the managers see the organisation's current EA maturity. Maturity can be assessed using different methods and models. One framework to use is Architecture Capability Maturity Model (ACMM) developed by US Department of Commerce [77]. 
The third quality to assess is the managers previous EA experience. In other words, have managers previously involved in EA initiatives in their current or previous organisations..

The fourth quality to assess is how complex the managers see the EA. Sometimes EA deliverables, such as, architecture descriptions, are seen too complex [78].

The fifth quality to assess is the managers authority on EA related matters. This is tightly coupled for the first assessed quality, i.e., is EA seen as business or IT oriented. For instance, if EA is seen as the glue between business and IT, CIO typically has all required authority. However, if EA is seen as the means for organisational innovation, typically only CEO has the required authority to make EA related decisions.

\subsubsection{Explain specific EA benefits}

The third phase of the Explain EA Benefits Process is to explain specific EA benefits according to each manager's views to EA as assessed in the previous phase. There are ten benefits to be explained as listed in Table 4 .

Table 4. EA views and benefits [adapted from 48]

\begin{tabular}{|c|c|c|c|c|c|c|c|}
\hline \multirow[t]{2}{*}{ EA View / Benefit } & Orientation & Maturity & \multicolumn{2}{|c|}{ Experience } & Complexity & \multicolumn{2}{|c|}{ Authority } \\
\hline & Bus. Tech. & Low High & Low & High & Low High & Low & High \\
\hline Adaptability and agility & $\mathrm{x}$ & $\mathrm{x}$ & $\mathrm{x}$ & & & & $\mathrm{x}$ \\
\hline $\begin{array}{l}\text { Increase operational } \\
\text { effectiveness }\end{array}$ & $\mathrm{x}$ & $\mathrm{x}$ & $\mathrm{x}$ & $\mathrm{x}$ & $\mathrm{x}$ & $\mathrm{x}$ & \\
\hline $\begin{array}{l}\text { Increase revenues and cost } \\
\text { reduction }\end{array}$ & $\mathrm{x}$ & $\mathrm{x}$ & $\mathrm{x}$ & & & & $\mathrm{x}$ \\
\hline Process improvement & $\mathrm{x}$ & $\mathrm{x}$ & $\mathrm{x}$ & & & & \\
\hline $\begin{array}{l}\text { Standardisation and } \\
\text { consistency }\end{array}$ & $\mathrm{x}$ & $\mathrm{x}$ & $\mathrm{x}$ & & & & $\mathrm{x}$ \\
\hline Win new business & $\mathrm{x}$ & $\mathrm{x}$ & $\mathrm{x}$ & & & & \\
\hline Planning & & & & $\mathrm{x}$ & $\mathrm{x}$ & $x$ & \\
\hline Product selection & & & & $\mathrm{x}$ & $\mathrm{x}$ & $\mathrm{x}$ & \\
\hline Speak a common language & & & & $\mathrm{x}$ & $\mathrm{x}$ & $\mathrm{x}$ & \\
\hline $\begin{array}{l}\text { Move the organisation } \\
\text { forward }\end{array}$ & & & & & & & $\mathrm{X}$ \\
\hline
\end{tabular}

The first benefit is Adaptability and agility. This refers to organisation's capability to respond to external events. For instance, the ability to quickly change organisational processes is currently seen as a strategic necessity [2].

The second benefit is Increase operational effectiveness. EA enables organisations to digitalise their processes. If this digitalisation is focused on the processes that do not change on regular basis, organisations may increase their operational effectiveness [2].

The third benefit is Increase revenues and cost reduction. EA provides details about the organisation's current state, including its business, information, information systems, and technology. Such information can used as a basis for removing overlapping assets and improving re-use. This can result to cost reduction and increased revenues. 
The fourth benefit is Process improvement. This benefit can partly be seen as a subset of the previous benefits. Information about the current business architecture, including processes, allows organisation to improve their processes. For instance, organisation may decide to adopt ITIL processes for their IT service management processes. However, the focus should be on those business processes where the most value can be realised.

The fifth benefit is Standardisation and consistency. Also this benefit is partly covered with previous benefits. Information about the current state of the organisation allows standardisation of, for instance, business processes, used vocabulary, desktop software, and server hardware. This, in turn, may lead to cost reduction and process improvement.

The sixth benefit is Win new business. This benefit can be seen as result of agility and standardisation. Agile organisation with standardised processes and operations may allow it to expand business to other markets and geographical areas [2].

The seventh benefit is Planning. This benefit refers to the organisational ability to change organisation in a planned way. This allows organisation to evolve proactively.

The eighth benefit is Product selection. This benefit refers to the ability to focus on those investments that provides the best value. The holistic information about the current state of the organisation allows assessing and selecting the investments which capture the most value.

The ninth benefit is Speak a common language. Describing the current and future states of the organisation in a formal way helps everyone to interpret and understand things in the same way. Using a formal and agreed notation notation helps to interpret descriptions even with low prior knowledge on the subject [79].

The tenth benefit is Move the organisation forward. This benefit refers to organisation's ability to achieve its goals. These goals can be described as the future state of the organisation and communicated using a common language. The managed change between the current and future states can be used to achieve the organisation's goals.

\subsection{Acquire Mandate}

The second phase of the EAAM is to acquire mandate from the top-management. This mandate can be, for instance, in a form of Request for Architecture Work (RAC) [13]. Typically the RAC is a high-level document including [13, p. 494]:

- Organisation sponsors

- Organisation's mission statement

- Business goals (and changes)

- Strategic plans of the business

- Time limits

- Changes in the business environment

- Organizational constraints

- Budget infor mation, financial constraints

- Exter nal constraints, business constraints

- Current business system description

- Current architecture/IT system description 
- Description of developing organization

- Description of resources available to developing organisation

The formal mandate emphasises the support from top-management, allowing smoother adoption process.

\subsection{Organise Enterprise Architecture Training}

The third phase of EAAM is to organise EA training see (Fig. 7). The purpose of the training is to increase organisation's EA knowledge to reduce organisational change resistance caused by the lack of EA knowledge.

\subsubsection{Assess organisation's learning stock}

The first phase of the Organise EA training process is to assess organisation's learning stock. As discussed earlier, organisational learning stock refers to knowledge embedded to organisation. E.g., organisation's structures, strategy, procedures, and culture [65]. Also organisation's capabilities are part of this learning stock. Typical organisational capabilities which EA adoption will affect are listed in Table 5.

Table 5. Organisational capabilities affected by EA adoption [13, p. 17]

\begin{tabular}{ll}
\hline Financial Management & Communications and Stakeholder Management \\
\hline Performance Management & Quality Management \\
\hline Service Management & Supplier Management \\
\hline Risk Management & Configuration Management \\
\hline Resource Management & Environment Management \\
\hline
\end{tabular}

Each of the mentioned capabilities are utilised during the EA adoption. Therefore the level of each capability should be assessed. Capabilities can be defined as tangible and intangible assets which organisations use to implement their strategies [80]. One example of these assets is the organisation's processes. For example, financial management capability consists of people and financial management processes. Thus the mature of the capability can be assessed by assessing the related processes.

There are many maturity models which could be utilised. Typically these models consists of 5 maturity levels. In TOGAF, process maturity is assessed using levels listed in Table 6. Another widely used framework is included in COBIT, which maturity levels are listed in Table 7.

Table 6. EA process maturity levels [13, pp. 685-689]

\begin{tabular}{ll}
\hline Level & Description \\
\hline $0:$ None & $\begin{array}{l}\text { No enterprise architecture program. No enterprise architecture to } \\
\text { speak of. }\end{array}$ \\
\hline 1: Initial & Informal enterprise architecture process underway. \\
\hline 2: Under development & Enterprise architecture process is under development. \\
\hline
\end{tabular}




\begin{tabular}{ll}
\hline 3: Defined & Defined enterprise architecture including detailed written procedures \\
\hline 4: Managed & Managed and measured enterprise architecture process. \\
\hline 5: Optimising & Continuous improvement of enterprise architecture process. \\
\hline
\end{tabular}

Table 7. COBIT process capability levels [75, p. 53]

\begin{tabular}{ll}
\hline Level & Description \\
\hline 0: Incomplete process & $\begin{array}{l}\text { The process is not implemented or fails to achieve its process } \\
\text { purpose. At this level, there is little or no evidence of any systematic } \\
\text { achievement of the process purpose. }\end{array}$ \\
\hline 1: Performed process & The implemented process achieves its process purpose. \\
\hline 2: Managed process & $\begin{array}{l}\text { The previously described performed process is now implemented in a } \\
\text { managed fashion (planned, monitored and adjusted) and its work } \\
\text { products are appropriately established, controlled and maintained. }\end{array}$ \\
\hline 3: Established process & $\begin{array}{l}\text { The previously described managed process is now implemented using } \\
\text { a defined process that is capable of achieving its process outcomes. }\end{array}$ \\
\hline 4: Predictable process & $\begin{array}{l}\text { The previously described established process now operates within } \\
\text { defined limits to achieve its process outcomes. }\end{array}$ \\
\hline 5: Optimising & $\begin{array}{l}\text { The previously described predictable process is continuously } \\
\text { improved to meet relevant current and projected business goals. }\end{array}$ \\
\hline
\end{tabular}

\subsubsection{Assess employee's learning stock}

The second phase of the Organise EA training process is to assess organisation's employees' learning stock. Employee's learning stock refers to employee's individual competence, capability, and motivation [65]. First step is to identify skill categories required in EA adoption. Typical skill categories are listed in Table 8. The next step is to assess employees' proficiency in each category. Proficiency levels can be assessed using levels listed in Table 9.

Table 8. EA team skill categories [13, p. 695]

\begin{tabular}{ll}
\hline Category & Description \\
\hline Generic Skills & $\begin{array}{l}\text { typically comprising leadership, teamworking, inter-personal } \\
\text { skills, etc. }\end{array}$ \\
\hline Business Skills \& Methods & $\begin{array}{l}\text { typically comprising business cases, business process, } \\
\text { strategic planning, etc. }\end{array}$ \\
\hline $\begin{array}{l}\text { Enterprise Architecture } \\
\text { Skills }\end{array}$ & $\begin{array}{l}\text { typically comprising modeling, building block design, } \\
\text { applications and role design, systems integration, etc. }\end{array}$ \\
\hline Program or Project & $\begin{array}{l}\text { typically comprising managing business } \\
\text { change, project management methods and tools, etc. }\end{array}$ \\
Management Skills & $\begin{array}{l}\text { typically comprising broker ing applications, asset } \\
\text { management, migration planning, SLAs, etc. }\end{array}$ \\
\hline IT General Knowledge & $\begin{array}{l}\text { typically comprising software engineering, security, data } \\
\text { Skills }\end{array}$ \\
\hline Technical IT Skills & \\
\hline
\end{tabular}


Legal Environment typically comprising data protection laws, contract law, procurement law, fraud, etc.

Table 9. Skills proficiency levels [13, p. 696]

\begin{tabular}{ll}
\hline Level & Description \\
\hline 1: Background & $\begin{array}{l}\text { Not a required skill, though should be able to define and manage skill } \\
\text { if required. }\end{array}$ \\
\hline 2: Awareness & $\begin{array}{l}\text { Understands the background, issues, and implications sufficiently to be } \\
\text { able to understand how to proceed further and advise client accordingly. }\end{array}$ \\
\hline 3: Knowledge & $\begin{array}{l}\text { Detailed knowledge of subject area and capable of providing professional } \\
\text { advice and guidance. Ability to integrate capability into architecture } \\
\text { design. }\end{array}$ \\
\hline 4: Expert & $\begin{array}{l}\text { Extensive and substantial practical experience and applied knowledge } \\
\text { on the subject. }\end{array}$ \\
\hline
\end{tabular}

\subsubsection{Use a proper leadership style}

The third phase of the Organise EA training process is to select and use a proper leadership style. Leadership style refers to the style which managers use to lead their organisation, project, or like. This style can be either transformational or transactional [67], as discussed earlier in sub-section 3.2. Characteristics of these styles are listed in Table 10 and Table 11, respectively. For short, transformational leadership style works best when change is needed in organisation and transactional leadership style when the current state needs to be enforced.

Using a proper leadership style while organising EA training is crucial. When the knowledge and skills required by EA adoption is challenging organisation's current learning stock, the transformational leadership style needs to be used [65]. Similarly, if the required knowledge and skills does not challenge organisation's current learning stock, the transactional leadership style should be used [65]. It should be noted that some capabilities may be in better shape while others. For instance, Supplier Management might be very mature while Risk Management might be practically non existing. In such case, transactional leadership style should be used while organising Supplier Management training, and transformational leadership style while organising Risk Management training.

Table 10. Characteristics of transformational leader [67, p. 22]

\begin{tabular}{ll}
\hline Characteristic & Description \\
\hline Charisma & $\begin{array}{l}\text { Provides vision and sense of mission, instills pride, gains } \\
\text { respect and trust. }\end{array}$ \\
\hline Inspiration & $\begin{array}{l}\text { Communicates high expectations, uses symbols to focus efforts, } \\
\text { expresses important purposes in simple ways. }\end{array}$ \\
\hline Intellectual Stimulation & Promotes intelligence, rationality, and careful problem solving. \\
\hline Individualised Consideration & $\begin{array}{l}\text { Gives personal attention, treats each employee individually, } \\
\text { coaches, advises. }\end{array}$ \\
\hline
\end{tabular}


Table 11. Characteristics of transactional leader [67, p. 22]

\begin{tabular}{ll}
\hline Characteristic & Description \\
\hline Contingent Reward & $\begin{array}{l}\text { Contracts exchange of rewards for effort, promises rewards for } \\
\text { good performance, recognises accomplishments. }\end{array}$ \\
\hline $\begin{array}{l}\text { Management by Exception } \\
\text { (active) }\end{array}$ & $\begin{array}{l}\text { Watches and searches for deviations from rules and standards, } \\
\text { takes corrective action. }\end{array}$ \\
\hline $\begin{array}{l}\text { Management by Exception } \\
\text { (passive) }\end{array}$ & Itervenes only if standards are not met. \\
\hline Laissez-Faire & Adbicates responsibilities, avoids making decisions. \\
\hline
\end{tabular}

\subsubsection{Promote EA training}

The fourth phase of the Organise EA training process is to promote EA training. Promoting refers to advertising the right training to right audience. The proper leadership style should be used during the promoting accordingly.

\subsubsection{Provide EA training}

The fifth phase of the Organise EA training process is to provide EA training. This is the most crucial phase of the Organising EA learning process. In this phase, the required knowledge and skills are taught to individuals, and eventually, to organisation. Training can be provided as any other training, e.g., internal or external instructor-led training, e-learning, and self-study.

\subsubsection{Use coercive organisational pressure}

The sixth phase of the Organise EA training process is to use the coercive organisational pressure. This means that as the new knowledge is trained and learned, applying this new knowledge needs to be enforced. Using coercive organisational pressure means adopting the transactional leadership style, focusing on searching deviations from using EA and taking corrective actions as required [67]. Coercive pressure has a crucial moderating role while assimilating EA to organisation's learning stock, but only when used as a temporary solution [64].

\subsection{Conduct Enterprise Architecture Adoption}

The fourth phase of EAAM is to conduct EA adoption (Fig. 3). In this phase the value and benefits of EA are realised as the organisation is adopting EA.

\subsubsection{Select EA framework}

The first phase of the Conduct EA Adoption Process is to select the EA framework. Typically, EA framework consists of governance model and development method, including management and utilisation processes, roles, and description templates. Some examples of EAFs are The Open Group Architecture Framework (TOGAF), The 
Department of Defence Architecture Framework (DoDAF), Federal Enterprise Architecture Framework (FEAF), and Capgemini's Integrated Architecture Framework (IAF). TOGAF is currently the de-facto standard and mostly used EAF in both public and private sector [81]. Organisations should select the framework that best suits for its purposes.

\subsubsection{Describe the current state}

The second phase of the Conduct EA Adoption Process is to describe the current state of the organisation. The descriptions to be produced depends on the selected EA framework and the purpose of adopting EA. Also the notation used to create the descriptions depends on the framework. However, some frameworks, such as TOGAF, does not contain any notation. In such case, it is recommended to use de-facto standard notations, such as, ArchiMate [82] and BPMN [83].

The descriptions of the current state should be value free, i.e., they should be objective representations of the reality without assessing the "goodness" of current solutions.

\subsubsection{Describe the future state}

The third phase of the Conduct EA Adoption Process is to describe the future state of the organisation. The descriptions of the future state should be produced using the same notation used to describe the current state. Organisation's strategic goals and decisions are embodied to future state descriptions and should be perceived similar way by everyone.

\subsubsection{Perform the managed change}

The fourth phase of the Conduct EA Adoption Process is to perform the managed change from the current state to the future state of the organisation. In this phase the organisation is changed to match the desired future state. The breadth and depth of the change depends on many things, such as, the strategic level of EA.

Organisation may use any methodology or processes to perform the change, as long as it is managed. For instance, organisation may utilise best practices like PRINCE2 [84].

\section{Conclusions}

As stated in the problem definition, the purpose of the EAAM is to improve the traditional EA adoption process to minimise the effects of lack of understanding EA and related concepts. For this purpose, EAAM introduced two new sub-processes: Explain EA benefits and Organise EA learning.

Goal of the Explain EA benefits process is to increase the likelihood of getting a mandate from top-management for EA adoption. This is achieved by explaining EA benefits based on each manager's characteristics. Experts' statements supports 
achievement of this goal strongly, as most of the statements are related to this process. This also indicates the importance of securing top-management mandate.

Goal of the Organise EA learning process is to increase the understanding of EA concepts. This is achieved by assessing the current learning stock and by providing appropriate training with a help of appropriate leadership style. Experts' statements supports also achievement of this goal.

According to March and Smith [85, p. 261] "Evaluation of methods considers operationality (the ability to perform the intended task or the ability of humans to effectively use the method if it is not algorithmic), efficiency, generality, and ease of use". The first two criteria, operationality and efficiency is evaluated above; EAAM can be used to perform intended task (e.g., adopt EA in an organisation) and it is efficient. The last two criteria, generality and ease of use, can be evaluated only by applying EAAM in other settings. The practical guidelines applying EAAM helps in assessing the generality and ease of use.

It cannot be argued that EAAM would be the best alternative solution to the traditional EA adoption method. However, as demonstrated in previous section, it can be argued that EAAM is better than the traditional EA adoption method.

\subsection{Limitations and Future Work}

As with all research this research is not without limitations. EAAM was evaluated with a panel of EA experts. Therefore, the first direction for future work is to evaluate it in a real-life setting by instantiation. To increase its generalisability, EAAM should be instantiated outside the Finnish public sector. In this paper, the ease-of-use of EAAM was not assessed. As suggested for instance by Venkatesh et al. [54], ease-of-use is important. Thus our second direction for future research is to assess EAAM's ease-ofuse in a real-life setting.

\subsection{Conclusion}

The EAAM method emphasises the importance of acquiring the mandate for EA adoption from the top-management and the importance of a proper EA training. EAAM helps in acquiring the mandate by formulating the argumentation of EA benefits according to the individual's interests. Moreover, EAAM helps in EA training by providing directions in choosing a proper leadership style to promote EA training. Thus by following EAAM, organisations can minimise the effects of the lack of EA knowledge.

To support the adoption of EAAM, some practical guidelines are provided. This should help practitioners in their EA adoption endeavours to realise EA benefits in their organisations.

\section{References}

1. Schulman, J.: Enterprise Architecture: Benefits and Justification. Gartner (2003) 
2. Ross, J.W., Weill, P., Robertson, D.C.: Enterprise architecture as strategy: Creating a foundation for business execution. Harvard Business School Press, Boston, Massachusetts, USA (2006)

3. Schekkerman, J.: Trends in Enterprise Architecture 2005: How are Organizations Progressing? Institute for Enterprise Architecture Developments, Amersfoort, Netherlands (2005)

4. Computer Economics, http://www.computereconomics.com/article.cfm?id=1947

5. Hjort-Madsen, K.: Enterprise Architecture Implementation and Management: A Case Study on Interoperability. In: HICSS-39. Proceedings of the 39th Annual Hawaii International Conference on System Sciences. (2006)

6. Sembiring, J., Nuryatno, E.T., Gondokaryono, Y.S.: Analyzing the Indicators and Requirements in Main Components Of Enterprise Architecture Methodology Development Using Grounded Theory in Qualitative Methods. Society of Interdisciplinary Business Research Conference, Bangkok (2011)

7. Valtonen, K., Mäntynen, S., Leppänen, M., Pulkkinen, M.: Enterprise Architecture Descriptions for Enhancing Local Government Transformation and Coherency Management: Case Study. In: Enterprise Distributed Object Computing Conference Workshops (EDOCW), 2011 15th IEEE International, pp. 360-369. (2011)

8. Lemmetti, J., Pekkola, S.: Understanding Enterprise Architecture: Perceptions by the Finnish Public Sector. In: Scholl, H., Janssen, M., Wimmer, M., Moe, C., Flak, L. (eds.) Electronic Government, vol. 7443, pp. 162-173. Springer, Berlin (2012)

9. Pehkonen, J.: Early Phase Challenges and Solutions in Enterprise Architecture of Public Sector. vol. Master's Degree Programme in Information and Knowledge Management, pp. 107. Tampere University of Technology, Tampere (2013)

10.Fehskens, L.: Len's Lens: Eight Ways We Frame Our Concepts of Architecture. Journal of Enterprise Architecture 11, 55-59 (2015)

11.Zachman, J.A.: Enterprise architecture: The issue of the century. Database Programming and Design 10, 44-53 (1997)

12.CIO Council: A Practical Guide to Federal Enterprise Architecture. (2001)

13. The Open Group: TOGAF Version 9. Van Haren Publishing, Zaltbommel, Netherlands (2009)

14.ISO/IEC/IEEE: Systems and software engineering -- Architecture description. ISO/IEC/IEEE 42010:2011(E) (Revision of ISO/IEC 42010:2007 and IEEE Std 14712000), pp. 1-46 (2011)

15.http://www.gartner.com/it-glossary/enterprise-architecture-ea/

16.Dietz, J.L.G., Hoogervorst, J.A.P., Albani, A., Aveiro, D., Babkin, E., Barjis, J., Caetano, A., Huysmans, P., Iijima, J., van Kervel, S.J.H., Mulder, H., Op ‘t Land, M., Proper, H.A., Sanz, J., Terlouw, L., Tribolet, J., Verelst, J., Winter, R.: The discipline of enterprise engineering. Int. J. Organisational Design and Engineering 3, 86-114 (2013)

17.Syynimaa, N.: Theoretical Perspectives of Enterprise Architecture. 4th Nordic EA Summer School, EASS 2013, Helsinki, Finland (2013)

18.van de Ven, A.H., Poole, M.S.: Explaining Development and Change in Organizations. The Academy of Management Review 20, 510-540 (1995)

19.North, E., North, J., Benade, S.: Information Management and Enterprise Architecture Planning--A Juxtaposition. Problems and Perspectives in Management 166-179 (2004)

20.Kaisler, H., Armour, F., Valivullah, M.: Enterprise Architecting: Critical Problems. Proceedings of the 38th Annual Hawaii International Conference on System Sciences., HICSS-38., pp. 224-234. IEEE, Washington, DC, USA (2005)

21.Shupe, C., Behling, R.: Developing and Implementing a Strategy for Technology Deployment. Information Management Journal 40, 52-57 (2006)

22. Gregor, S., Jones, D.: The anatomy of a design theory. Journal of the Association for Information Systems 8, 312-335 (2007) 
Method and Practical Guidelines for Overcoming Enterprise Architecture Adoption Challenges

23.Iyamu, T.: Enterprise Architecture as Information Technology Strategy. In: Commerce and Enterprise Computing (CEC), 2011 IEEE 13th Conference on, pp. 82-88. (2011)

24.Iyamu, T.: The Factors Affecting Institutionalisation of Enterprise Architecture in the Organisation. . In: Hofreiter, B., Werthner, H. (eds.) Proceedings of the IEEE Conference on Commerce and Enterprise Computing, CEC '09. , pp. 221-225. IEEE, Los Alamitos, California, United States (2009)

25.Liu, Y., Li, H.: Applying Enterprise Architecture in China E-Government: A Case of Implementing Government-Led Credit Information System of Yiwu. In: WHICEB2009. Eighth Wuhan International Conference on E-Business, pp. 538-545. (2009)

26.Carrillo, J., Cabrera, A., Román, C., Abad, M., Jaramillo, D.: Roadmap for the implementation of an enterprise architecture framework oriented to institutions of higher education in Ecuador. In: Software Technology and Engineering (ICSTE), 2010 2nd International Conference on, pp. V2-7-V2-11. IEEE, (2010)

27.Mezzanotte, D.M., Dehlinger, J., Chakraborty, S.: On Applying the Theory of Structuration in Enterprise Architecture Design. In: Computer and Information Science (ICIS), 2010 IEEE/ACIS 9th International Conference on, pp. 859-863. (2010)

28.Vasilescu, C.: General Enterprise Architecture Concepts and the Benefits for an Organization. 7th International Scientific Conference, Defence Resources Management in the 21st Century, pp. 1-9. Romanian National Defence University, Regional Department of Defence Resources Management Studies, Braşov (2012)

29.Struijs, P., Camstra, A., Renssen, R., Braaksma, B.: Redesign of Statistics Production within an Architectural Framework: The Dutch Experience. Journal of Official Statistics 29, 49-71 (2013)

30.Hammer, M., Champy, J.: Reengineering the corporation: a manifesto for business revolution. Nicholas Brearly, London (1993)

31.Beer, M., Nohria, N.: Cracking the code of change. Harvard Business Review 78, 133-141 (2000)

32.Kotter, J.P.: A sense of urgency. Harvard Business Press, Harvard, United States (2008)

33. Finnish Ministry of Finance: Act on Information Management Governance in Public Administration (643/2011). (2011)

34.Finnish Ministry of Finance: Tietoja valtion tietohallinnosta 2014. Valtiovarainministeriön julkaisuja 27/2015. (Information on the state information management 2014. Publications of the Ministry of Finance 27/2015). pp. 60. Ministry of Finance, Helsinki (2015)

35.Hiekkanen, K., Korhonen, J.J., Collin, J., Patricio, E., Helenius, M., Mykkanen, J.: Architects' Perceptions on EA Use -- An Empirical Study. . In: O'Conner, L. (ed.) Proceedings of the 15th IEEE Conference on Business Informatics (CBI), pp. 292-297. IEEE, Los Alamitos, California, United States (2013)

36. Seppänen, V.: From problems to critical success factors of enterprise architecture adoption. Jyväskylä studies in computing, vol. 201, pp. 250. University of Jyväskylä, Jyväskylä (2014)

37. Syynimaa, N.: Enterprise Architecture Adoption Method for Higher Education Institutions., pp. 262. Gerenios Ltd, Tampere, Finland (2015)

38.Hevner, A., March, S., Park, J., Ram, S.: Design Science in Information Systems Research. MIS Quarterly 28, 75-106 (2004)

39.van Aken, J.E.: Management Research Based on the Paradigm of the Design Sciences: The Quest for Field-Tested and Grounded Technological Rules. Journal of Management Studies 41, 219-246 (2004)

40.Vaishnavi, V., Kuechler, B.: Design Science Research in Information Systems. desrist.org (2013)

41.Lee, A.S., Manoj, T.A., Baskerville, R.L.: Going Back to Basics in Design: From the IT Artifact to the IS Artifact. In: Proceedings of the Nineteenth Americas Conference on Information Systems, pp. 1-7. (2013) 
42.Peffers, K., Tuunanen, T., Rothenberger, M.A., Chatterjee, S.: A Design Science Research Methodology for Information Systems Research. Journal of management information systems 45-77 (2007)

43.Houkes, W.N.: Rules, Plans and the Normativity of Technological Knowledge. In: de Vries, M.J., Hansson, S.O., Meijers, A.W.M. (eds.) Norms in Technology, vol. 9, pp. 35-54. Springer (2013)

44.Bunge, M.: Technology as Applied Science. Technology and Culture 7, 329-347 (1966)

45.Järvinen, P.: On Design Research - Some Questions and Answers. In: Matulevičius, R., Dumas, M. (eds.) Perspectives in Business Informatics Research, vol. 229, pp. 113-125. Springer International Publishing (2015)

46.Skulmoski, G.J., Hartman, F.T., Krahn, J.: The Delphi Method for Graduate Research. Journal of Information Technology Education 6, 1-21 (2007)

47.Päivärinta, T., Pekkola, S., Moe, C.E.: Grounding Theory from Delphi Studies. Thirty Second International Conference on Information Systems, pp. 1-14, Shanghai (2011)

48.Nassiff, E.: Understanding the Value of Enterprise Architecture for Organizations: A Grounded Theory Approach. vol. 3523496, pp. 135. Nova Southeastern University, Ann Arbor (2012)

49. Burnes, B., James, H.: Culture, cognitive dissonance and the management of change. International Journal of Operations \& Production Management 15, 14-33 (1995)

50.Jones, R.A., Jimmieson, N.L., Griffiths, A.: The Impact of Organizational Culture and Reshaping Capabilities on Change Implementation Success: The Mediating Role of Readiness for Change. Journal of Management Studies 42, 361-386 (2005)

51.Holt, D.T., Armenakis, A.A., Feild, H.S., Harris, S.G.: Readiness for Organizational Change: The Systematic Development of a Scale. The Journal of Applied Behavioral Science 43, 232-255 (2007)

52. Washington, M., Hacker, M.: Why change fails: knowledge counts. Leadership \& Organization Development Journal 26, 400-411 (2005)

53.Elving, W.J.L.: The role of communication in organisational change. Corporate Communications: An International Journal 10, 129-138 (2005)

54.Venkatesh, V., Morris, M.G., Davis, G.B., Davis, F.D.: User acceptance of information technology: Toward a unified view. MIS Quarterly 27, 425-478 (2003)

55.Koponen, E.: The development, implementation and use of e-learning: critical realism and design science perspectives. University of Tampere (2009)

56.Lee, A.S.: Retrospect and prospect: information systems research in the last and next 25 years. Journal of Information Technology 25, 336-348 (2010)

57.Lee, A.S.: Thinking about Social Theory and Philosophy for Information Systems. In: Mingers, J., Willcocks, L. (eds.) Social Theory and Philosophy for Information Systems, pp. 1-26. John Wiley \& Sons, Chichester (2004)

58. Mintzberg, H., Ahlstrand, B., Lampel, J.: Strategy Safari: the Complete Guide Trough the Wilds of Strategic Management. Financial Times Prentice Hall, London (1998)

59.March, J.G., Simon, H.A.: Organizations. John Wiley \& Sons, Oxford (1958)

60. Kitchen, P.J., Daly, F.: Internal communication during change management. Corporate Communications: An International Journal 7, 46-53 (2002)

61.Hazen, B.T., Kung, L., Cegielski, C.G., Jones-Farmer, L.A.: Performance expectancy and use of enterprise architecture: training as an intervention. Journal of Enterprise Information Management 27, 6-6 (2014)

62.Knowles, M.S.: The Modern Practice of Adult Education. New York Association Press, New York (1970)

63.Mezirow, J.: Transformative Learning: Theory to Practice. New Directions for Adult and Continuing Education no. 74, 5-12 (1997) 
Method and Practical Guidelines for Overcoming Enterprise Architecture Adoption Challenges

64. Makiya, G.K.: A multi-level investigation into the antecedents of Enterprise Architecture (EA) assimilation in the U.S. federal government: a longitudinal mixed methods research study. vol. 3530104, pp. 296. Case Western Reserve University, Ann Arbor (2012)

65.Vera, D., Crossan, M.: Strategic Leadership and Organizational Learning. The Academy of Management Review 29, 222-240 (2004)

66.Crossan, M.M., Lane, H.W., White, R.E.: An organizational learning framework: from intuition to institution. Academy of management review 522-537 (1999)

67.Bass, B.M.: From Transactional to Transformational Leadership: Learning to Share the Vision. Organizational Dynamics 18, 19-31 (1990)

68.Espinosa, J.A., Armour, F., Boh, W.F.: The Role of Group Cognition in Enterprise Architecting. In: System Sciences (HICSS), 2011 44th Hawaii International Conference on, pp. 1-10. (2011)

69.Oxford University Press, http://oxforddictionaries.com/

70.Cannon-Bowers, J.A., Salas, E.: Reflections on Shared Cognition. Journal of Organizational Behavior 22, 195-202 (2001)

71.Agarwal, R.: Individual acceptance of information technologies. In: Zmud, R.W. (ed.) Framing the domains of IT management: Projecting the future through the past, pp. 85-104. Pinnaflex Education Resources, Cincinnati, OH (2000)

72.Venable, J., Pries-Heje, J., Baskerville, R.: A Comprehensive Framework for Evaluation in Design Science Research. In: Peffers, K., Rothenberger, M., Kuechler, B. (eds.) Design Science Research in Information Systems. Advances in Theory and Practice, vol. 7286, pp. 423-438. Springer Berlin Heidelberg (2012)

73.Stevens, S.S.: On the Theory of Scales of Measurement. Science, New Series 103, 677-680 (1946)

74.Luftman, J.: Assessing business-IT alignment maturity. Communications of Association for Information Systems 4, Article 14 (2000)

75.ISACA: COBIT® ${ }^{8}$. A Business Framework for the Governance and Management of Enterprise IT. ISACA, Rolling Meadows, IL, USA (2012)

76.Lapalme, J.: Three Schools of Thought on Enterprise Architecture. IT Professional 14, 37 $43(2012)$

77.http://ocio.os.doc.gov/ITPolicyandPrograms/Enterprise_Architecture/PROD01_004935

78.van der Raadt, B., Schouten, S., van Vliet, H.: Stakeholder perception of enterprise architecture. In: ECSA 2008, Second European Conference on Software Architecture, pp. 19-34. Springer, (2008)

79.Mayer, R.E., Gallini, J.K.: When is an illustration worth ten thousand words? Journal of Educational Psychology 82, 715-726 (1990)

80.Ray, G., Barney, J.B., Muhanna, W.A.: Capabilities, business processes, and competitive advantage: choosing the dependent variable in empirical tests of the resource-based view. Strategic management journal 25, 23-37 (2004)

81.Cameron, B.H., McMillan, E.: Analyzing the Current Trends in Enterprise Architecture Frameworks Journal of Enterprise Architecture 9, 60-71 (2013)

82.http://www.opengroup.org/subjectareas/enterprise/archimate

83.http://www.omg.org/spec/BPMN/2.0/

84.https://www.axelos.com/best-practice-solutions/prince2

85.March, S.T., Smith, G.F.: Design and natural science research on information technology. Decision Support Systems 15, 251-266 (1995) 